\title{
Análisis pragmático-cognitivo de tres versiones en español de The Tell-Tale Heart de Edgar Allan Poe
}

\author{
(A Cognitive Analysis of Three Spanish \\ Versions of Edgar Allan Poe's The Tell-Tale Heart)
}

ROSALÍA VILLA JIMÉNEZ rosalievj1212@gmail.com

Universidad de Córdoba

Fecha de recepción: 18 de junio de 2015

Fecha de aceptación: 1 de julio de 2015

Resumen: En el presente trabajo se van a analizar cuatro fragmentos extraídos de tres versiones en español de The Tell-Tale Heart bajo el prisma pragmático-cognitivo de la traducción propuesto por Ernst-August Gutt (1989). Este enfoque se fundamenta en las propuestas de la comunicación cognitiva de Dan Sperber y Deirdre Wilson (1986) y su Teoría de la Relevancia. De este modo, E. A. Gutt concibe el fenómeno de la traducción como un ejemplo de "semejanza interpretativa", que ocurre en el acto de comunicación ostensivo-inferencial. De forma más concreta, en este artículo se van a plasmar los recursos interpretativos que el traductor como receptor de una obra literaria pone en funcionamiento cuando infiere los contenidos implícitos del texto origen (mismas proposiciones y semejantes implicaturas) y después los transmite al lector del texto meta.

Palabras clave: Ficción gótica, Comunicación ostensiva, Efectos cognitivos, Semejanza interpretativa.

Abstract: The primary objective of the current study is to perform an analysis of four excerpts taken from three Spanish versions of The Tell-Tale Heart from Ernst-August Gutt's (1989) cognitive approach to translation. This translation perspective is fundamentally rooted in Dan Sperber and Deirdre Wilson's (1986) cognitive proposal and their Principle of Relevance. E. A. Gutt conceives of translation as an example of interpretive resemblance, which occurs in the act of inferential ostensive communication. More specifically, this study focuses on exploring the interpretive resources activated by the translator as a receptor of a literary text when inferring the implicit content from the source text —same propositions and resembling implicatures- and communicating them to the target text reader. 
Key Words: Gothic fiction, Ostensive communication, Cognitive effects, Interpretive resemblance.

\section{Los Pilares DEL TRASCENDENTALISMO}

La primera mitad del siglo XIX constituye "'the Romantic period in American literature', which occurred about a generation after the Romantic Movement in European literature" (Pakditawan, 2007: 6). El movimiento romántico se inicia en Estados Unidos con una generación de escritores cuyas producciones literarias conformarán una identidad que, aunque retoma muchas premisas de la tradición literaria inglesa, supondrá el renacer de una expresión artística propia. De este modo, el crítico literario Matthiessen (1941) denomina a este renacimiento artístico, que surge con el antebellum norteamericano, "American Renaissance" (Matthiessen, 1941: 5), una etapa que "has long been recognized as the richest in America's literary history, the period that produced R. W. Emerson, H. Thoreau, N. Hawthorne, H. Melville, E. A. Poe, W. Whitman, and E. Dickinson" (Reynolds, 2011: 3).

R. W. Emerson (1803-1882) se consideraría el padre de este "American Renaissance" tras la publicación de su ensayo "Nature" (1836), en el que pone de manifiesto los principios del Trascendentalismo, movimiento que se origina como respuesta a la industrialización, a los fines expansionistas, a las tensiones sociales y políticas y a la esclavitud de la primera mitad del siglo XIX (Robinson, 1999: 17). En este contexto, el Trascendentalismo aboga por la reforma en la educación, por la libertad, el abolicionismo y, por último, por "a culture of peaceable, noncompetitive political and economic accord in which individuals might (...) develop their own interests and potential" (Robinson, 1999: 21-23). De igual modo, este movimiento se fundamenta en los preceptos ontológicos, metafísicos y epistemológicos, más en concreto, en las "creencias sobre la naturaleza de la realidad última, es decir, Dios" y las "creencias sobre las facultades y condiciones del conocimiento de las realidades por parte del hombre" (Coy, 2011: 82).

\footnotetext{
1 "La conciencia de todo individuo tiene su correlato en la naturaleza, la cual se constituye como la proyección de su interioridad; la naturaleza a su vez es una manifestación de Dios" (Cervantes, 1997: 181). De este modo, el trascendentalista, al igual que el romántico inglés, se reencuentra con lo primitivo, fuente de inspiración de la belleza y lo divino, que internaliza y exterioriza desde la subjetividad, fruto de sus emociones e intuición. El individuo se libera de las instituciones sociales y tradiciones y emprende su crecimiento espiritual fundamentado en la intuición con el fin de alcanzar su autodescubrimiento (Goodman, 1990).
} 
Aparte de recibir las influencias filosóficas de I. Kant (1724-184) o F. W. J. von Schelling (1775-1854), ${ }^{2}$ el Trascendentalismo recibe, sobre todo, la influencia del Romanticismo inglés y del Unitarismo, una corriente de pensamiento teleológica (1790-1815) que revisa los dogmas calvinistas y puritanos a favor de la libertad del individuo no corrompido por las instituciones sociales (Parrington, 1987: 322). ${ }^{3}$ En otras palabras, "nature is improbable through nurture and self-culture rather than corrupt beyond hope without conversion through a special act of divine grace" (Buell, 1988: 365).

En última instancia, el Trascendentalismo realza la relación del individuo con la naturaleza como una expresión de integridad que la industrialización, la expansión colonial y la urbanización eclipsan, "the moral, spiritual, and national integrity of American culture rested upon the citizenry's relationship to the natural landscape and its gentle cultivation" (Taylor, 2005: 1424). En esta estela, descuellan los célebres escritores $R$. W. Emerson, H. D. Thoreau y W. Whitman, entre otros.

A modo de conclusión, el Trascendentalismo constituye una llamada a la reforma, a la libertad, a la intuición y al individualismo, así como también a la reflexión y al autodescubrimiento en la naturaleza y en la gracia divina.

\section{EL ROMANTICISMO OSCURO Y EL GÉNERO GÓTICO}

En la primera mitad del siglo XIX, el Romanticismo norteamericano, que encuentra su expresión en el Trascendentalismo, se caracteriza por fundamentarse en el idealismo y el Unitarismo que subrayan la libertad individual y la benevolencia de la naturaleza, del hombre y de Dios. Críticos como Alsen (2000) apelan a este período como "Positive Romanticism". Por su parte, Foerster (1957) resume algunos de los principios románticos y trascendentalistas que constituyen el citado "Positive Romanticism":

\footnotetext{
${ }^{2}$ Los filósofos idealistas alemanes Kant (Kritik der reinen Vernunft, 1781, Crítica de la razón pura) y Schelling (System des transzendentalen Idealismus, 1800, Sistema del idealismo trascendental) ejercen una gran influencia en el Trascendentalismo. Por un lado, se destaca la búsqueda kantiana del conocimiento, que se concibe como la síntesis entre los conceptos que son el producto de la razón subjetiva y las impresiones. Por otro lado, la filosofía trascendentalista de Schelling considera que "todo lo natural es una parte de un gran superorganismo" (Irisarri Vázquez, 2008: 126), por lo que el ser humano constituye una parte del todo de la naturaleza.

${ }_{3}$ El Romanticismo inglés se caracteriza por desligarse, aunque paulatinamente, del pensamiento filosófico y la tradición estética del siglo XVIII. Este movimiento adopta una nueva concepción de libertad e individualismo, "It not only offered an escape from society but also was an ideal stage for the Romantic individual to exercise the cult that he frequently made of his own soul" (Nash, 2001: 47).
} 
The world we live in is not a dead machine, but rather a living, breathing being. God is not outside the universe, forgetting and forgotten, but in it and in us, an immanent presence (...). Reality was to be sought not through conscious but through immediate intuitive perception: the kingdom of God was within. (Foerster, 1957: 257-258).

Por otro lado, el pensamiento norteamericano adopta de la tradición europea una actitud que subvierte el optimismo trascendentalista y que se define como "the expression of the attitudes, feelings and ideas of a man who has left static mechanism but has not yet arrived at a reintegration of his thought and art in terms of dynamic organicism" (Pekcham, 1951: 15). A esta vertiente del Romanticismo que refleja la dicotomía entre una visión mecanicista y una orgánica del mundo se le denomina "Negative Romanticism" o "Dark Romanticism" (Alsen, 2000).

Esta perspectiva romántica pesimista plasma la incertidumbre, la decadencia, el conflicto interior, la culpa, la locura y el temor propios de un periodo de reformas religiosas, de expansion y explotación colonial, de esclavitud y lucha por su abolición, y del redescubrimiento del individuo como un ser alienado, sombrío, depravado, salvaje y destructivo. Hume (1974) habla sobre el "Dark Romanticism" en términos de:

(1) Doubt, despair, and personal and religious alienation; (2) the exploration of dilemma, ugliness, and perversion; (3) the fascination with evil and pain; (4) disbelief in love and human compassion (...) an acute perception of evil with little move toward either solution or escape, [what he calls] Existential Agony. (Hume, 1974: 112-123).

Por ende, el género gótico norteamericano, distintivo de los estados sureños a partir de E. A. Poe, destaca por ser una expresión regional de otredad, lúgubre y disociada, "becoming the repository for everything from which the nation wants to disassociate itself" (Goddu, 1997: 3-4). En esta línea, Walsh (2013) expone que el sur de los Estados Unidos constituye un claro ejemplo de la situación paradójica de una nación que se nutre de valores utópicos pero que, a su vez, entraña una realidad muy diferente, "The nation that espoused equality and freedom also initiated a Gothic tradition that articulated cultural anxieties about denial and marginalization" (Walsh, 2013: 20). En pocas palabras, la literatura gótica es una crítica al mito de un nuevo mundo teñido de inocencia y libertad, de igualdad, unidad y pureza.

El escritor del género gótico, bajo el influjo de la desesperanza y el vacío del individuo, hace partícipe al lector del estado de obsesión, agonía y ansiedad de sus personajes. Para ello, se surte de la exploración psicológica, sobre todo, pesimista de estos seres ficticios y de la revelación 
de lo grotesco y del horror. En este tipo de género, los personajes se debaten entre la racionalidad y la irracionalidad, la razón y las pasiones, a la vez que sucumben ante la oscuridad, la soledad y el pesimismo que la realidad, proyección de su propia angustia, les presenta (Dínçer, 2010).

Como colofón, numerosos críticos apuntan que el "Dark Romanticism" se hace eco de una realidad particular norteamericana. La visión pesimista de una nación utópica se aleja del optimismo característico del Trascendentalismo y del "Positive Romanticism". La ficción gótica ahonda en el terror, el miedo y la irracionalidad como exponentes de una realidad abrumadora que escritores como E. A. Poe, H. Melville o N. Hawthorne exploran mediante personajes melancólicos y torturados hasta el borde de la locura y un simbolismo desolador de la naturaleza.

\section{E. A. POE: EL TERROR EN EL RELATO CORTO ${ }^{4}$}

E. A. Poe (1809-1849) se considera una de las figuras más representativas de la tradición literaria gótica norteamericana del siglo XIX. La identidad sureña, que nace de una región agraria a favor de la esclavitud, se representa en la creación literaria por medio de la tradición romántica inglesa. Escritores como W. G. Simms (1806-1870), por ejemplo, se inclinan por la belleza del paisaje, el idealismo, la autonomía del Sur, los ideales de caballería, la vida idílica en las plantaciones y la correcta actuación de las instituciones (Thompson, 1988). ${ }^{5}$ Por el contrario, E. A. Poe profundiza en la temática de la irracionalidad, la belleza grotesca, la delgada línea entre la mortalidad y la inmortalidad, la corrupción de la realidad social y el terror.

En su ensayo "Philosophy of Composition" (1846), explica que toda obra literaria debe leerse "at one sitting [thus] we must be content to dispense with the immensely important effect derivable from unity of impression" (Galloway, 2003: 432). En consecuencia, el relato corto se convierte en el género textual por excelencia para la "unidad de impresión" con el que el escritor crea, además, lo que él denomina "unidad de efecto",

\footnotetext{
${ }^{4}$ Los relatos cortos de Poe constituyen una nueva concepción literaria que el autor utiliza para ofrecer al lector una exploración de los estados psicológicos de sus personajes, del desequilibrio del individuo, que desemboca en episodios psicóticos y en el delirio, y una temática que gira en torno a la muerte y lo fantasmagórico, leitmotiv de su propia experiencia. ${ }^{5}$ Poe consigue reconocimiento profesional en el Sur gracias a la revista Southern Literary Messenger. Su estilo no es siempre formal y la temática de sus obras entrelaza la idealización de la mujer con los elementos grotescos y satíricos. De igual manera, sus obras no abordan cuestiones raciales o la esclavitud, así como tampoco confrontan personajes del Norte con los del Sur. Estos son algunos de los aspectos que distancian al escritor de la literatura sureña (Thompson, 1988). Poe recibe la influencia de S. T. Coleridge, G. G. (Lord) Byron, J. Keats y P. B. Shelley, así como de la tradición gótica alemana. Se le considera precursor de la escuela simbolista francesa, de la novela policíaca de Arthur Conan Doyle y del género de ciencia ficción (Galloway, 2003).
} 
es decir, lograr que el efecto de horror o melancolía, así como la exageración de los elementos góticos se preserven en su totalidad. Para el autor, que la lectura de un relato exceda las dos horas supone que la extensión de la obra ha superado los límites, lo que conlleva la ruptura de la "unidad de efecto" del relato (Galloway, 2003: 432). Así pues, la brevedad de la narración constituye un elemento esencial en el proceso creativo.

La mayoría de sus relatos cortos ponen de relieve la decadencia del ser humano en situaciones límites, que se manifiesta mediante la lucha interna del individuo contra la locura, la enfermedad y la desintegración, "the mind attempts to preserve itself from its own forces of madness, disease, and disintegration by rigidly isolating itsefl and by assuming that the threat is external when in fact it is internal" (Shulman, 1970: 248). El entorno aparece subyugado a los estados anímicos y mentales perturbados del personaje, de tal manera que la realidad externa cobra un sentido aterrador. En este mundo interior irracional, la perversidad como impulso incontrolable que conduce a la vileza también adquiere un papel importante:

\begin{abstract}
El terror y la muerte constituyen motivos omnipresentes; la descripción de estados anímicos, mayoritariamente de degeneración psíquica; el entorno como reflejo del mundo interior de los protagonistas, y, a su vez, la influencia del medio ambiente en la evolución y estado mental de los personajes (...) acuciados por la ansiedad y dotados de una extraordinaria agudeza en el percepción sensorial. (Castillo, 2010: 12).
\end{abstract}

Al igual que la figura del trascendentalista, los protagonistas de $\mathrm{E}$. A. Poe encarnan a un individuo que se rebela contra las normas de la sociedad, pero este las transgrede hasta alcanzar su autodestrucción por medio de la locura y la alienación, "Poe's primary concern is (...) with madness as a reflection of alienation from the human community, as a consequence of loneliness, as the symbol of the deterioring effect of sin on unrepented consciousness" (Álvarez Faedo, 1997: 115). La espacialización, igualmente, contribuye a la irracionalidad y autolisis de los personajes. E. A. Poe, para este fin, recurre a microcosmos aislados y sombríos, representativos de la decadencia de la naturaleza. Elementos creativos como la musicalidad con la que las emociones y el entorno se describen y el ritmo y la adjetivación con la que el nerviosismo y el miedo de sus personajes se expresan intensifican el efecto estético del terror. En algunos relatos, por ejemplo The Tell-Tale Heart o The Cask of the Amontillado, el escritor introduce lo que los críticos han acuñado como "Romantic irony" (Thompson, 1973), es decir, un tipo de "humour understood as cynical humour, the pleasure of the murderer to execute his victim" (Popescu, 1012: 4), que subraya la frialdad de los personajes, su locura y su depravación. 
En resumen, la filosofía cosmológica de E. A. Poe subyace en una teoría literaria que consiste en la "unidad de efecto" como principio regulador de toda expresión artística. El estado de desintegración que experimenta el universo conforma los mundos creados en los relatos del escritor, que ponen de manifiesto los rasgos definitorios del género gótico y del "Dark Romanticism". Sus relatos revelan una tensión entre la prosa estructurada y la temática oscura empleada, ahondan en el caos y la desintegración, en la lucha constante entre las fuerzas de la racionalidad y la irracionalidad, y culminan en un final trágico para sus personajes.

\section{LA TEORÍA de LA ReLEVANCIA DE SPERBER Y WILSON}

La Teoría de la Relevancia propuesta por D. Sperber y D. Wilson (1986) se explica como un modelo cognitivo que se aleja de la visión tradicional sobre la comunicación humana fundamentada en un modelo de codificación y decodificación. ${ }^{6}$ Se puede argüir que la Teoría de la Relevancia (de aquí en adelante "TR") comienza a germinar a partir de las tesis que H. P. Grice (1975) asienta sobre el acto comunicativo como modelo inferencial. Según este modelo, el receptor infiere las intenciones del emisor mediante el input (estímulo) recibido que, a su vez, genera una serie de expectativas que guían al receptor para su correcta interpretación. Estas expectativas se establecen en función de un principio regulador de todo acto comunicativo, el Principio de Cooperación, y de un conjunto de máximas (cantidad, calidad, relevancia y manera), de entre las que se destaca la máxima de la relevancia (Grice, 1975: 45). ${ }^{7}$

A partir de este modelo cooperativo, Sperber y Wilson continúan las premisas establecidas por Grice para el desarrollo de "an inferential model of communication" (Sperber and Wilson, 2004: 607). De este modo, asientan los siguientes principios básicos de la Teoría de la Relevancia:

The goal of inferential pragmatics is to explain how the hearer infers the speaker's meaning on the basis of the evidence provided. The relevance-theoretic account is based on another of Grice's central claims: that utterances automatically create expectations which guide the hearer towards the speaker's meaning. Grice described these expectations in terms of a Co-operative Principle and maxims of

\footnotetext{
${ }^{6}$ Véase The Mathematical Theory of Communication (1964) de Claude E. Shannon y W. Weaver.

${ }^{7}$ Grice argumenta que se deben destacar cuatro categorías principales, "Quantity, Quality, Relation and Manner" (Grice, 1975: 45), mediante las que se articula una serie de máximas que deben cumplirse. En términos generales, estas categorías se pueden resumir en: la información que se aporta en el intercambio comunicativo no debe tener ni más ni menos cantidad de la necesaria, debe ser veraz, relevante respecto del tema tratado y debe ser clara y precisa.
} 
Quality (truthfulness), Quantity (informativeness), Relation (relevance) and Manner (clarity) which speakers are expected to observe. (Sperber y Wilson, 2004: 607).

El modelo inferencial de Sperber y Wilson gira en torno a la noción de "relevancia" como principio fundamental para que se produzca el acto comunicativo. Según Sperber y Wilson, "los enunciados suscitan una serie de expectativas de relevancia (...) porque la búsqueda de la relevancia es una característica fundamental del conocimiento humano de la que los hablantes tienden a aprovecharse" (Sperber y Wilson, 2004: 239). Estas expectativas de relevancia solo se producen cuando cualquier input, ya sea un enunciado, un sonido, etc., sea relevante para el oyente.

Según la TR, un input es relevante siempre y cuando modifique de alguna manera la información almacenada del receptor al entrar en contacto con este. Durante el acto comunicativo, el receptor procesa el input recibido que genera una serie de resultados denominados "efectos cognitivos positivos" o "efectos contextuales" al interactuar con la información almacenada que ya posee: "relevant information must in some sense 'link up' with other information one already has" (Gutt, 1996: 242). Sperber y Wilson definen los "efectos cognitivos positivos" como "una diferencia significativa para la representación mental que un sujeto tiene del mundo" (Sperber y Wilson, 2004: 240).

De este modo, estos autores establecen la siguiente relación: cuanto mayores sean los efectos cognitivos, mayor será la relevancia del input (Sperber y Wilson, 2004). Aun así, el factor principal que determina la relevancia no solo hace referencia al número de efectos cognitivos generados, sino también al esfuerzo requerido para el procesamiento del input emitido. En términos de la TR, cuanto mayor esfuerzo se requiera para inferir las suposiciones contextuales que el emisor ha querido transmitir, menos relevante será el input para el receptor.

Asimismo, la TR se fundamenta en dos principios básicos: el Principio Cognitivo de Relevancia y el Principio Comunicativo de Relevancia. En el primero, los procesos cognitivos están ligados a la obtención del mayor grado de relevancia. El receptor dispone de un conjunto de expectativas que lo alertan de que el input recibido emite una amalgama de suposiciones contextuales relevantes que transmiten un contenido altamente interesante como para realizar su procesamiento y obtener su interpretación. ${ }^{9} \mathrm{Tal}$ y

\footnotetext{
${ }^{8}$ Traducción española de Francisco Campillo García. En: The Handbook of Pragmatics. Oxford: Blackwell, 2004, pp. 607-32.

${ }^{9}$ Sperber y Wilson arguyen que la comunicación ostensivo-inferencial consiste en dos tipos de intenciones: una informativa y otra comunicativa, "la intención de informar a un interlocutor (...) [y] la intención de informar a un interlocutor de una intención propia" (Sperber y Wilson, 2004: 244).
} 
como se ha mencionado anteriormente, las suposiciones contextuales del hablante que nacen del enunciado o del texto son solamente relevantes para el receptor si producen numerosos efectos cognitivos y el receptor ha de realizar un menor esfuerzo para procesar el input.

Estos efectos son el resultado de la combinación entre la información transmitida por el input y los supuestos que el oyente posee sobre su percepción y conocimiento del mundo. Sperber y Wilson distinguen tres tipos de efectos: de refuerzo, eliminatorios (cuando existe contradicción entre la información previa y la recientemente adquirida), de debilitación, y los que contribuyen a la manifestación de nuevas implicaciones contextuales (nuevas suposiciones contextuales que se derivan de la deducción de la síntesis entre la información nueva y anterior). En relación a la TR, los supuestos contextuales conforman lo que Sperber y Wilson denominan contexto cognitivo, "A psychological construct, a subset of the hearer's assumptions about the world. It is these assumptions, of course, rather than the actual state of the world, that affect the interpretation of an utterance" (Sperber y Wilson, 1986: 15).

Por su parte, E. A. Gutt (1996) explica la noción de "contexto cognitivo" como un subconjunto de los supuestos que el oyente posee sobre el mundo, es decir, son todos los elementos que pueden desempeñar alguna función en la interpretación (Gutt, 1996: 28) ${ }^{10}$. Este contexto cognitivo se selecciona una vez que la suposición contextual se interpreta como relevante en aras de la maximización de la relevancia y la producción del acto comunicativo, que se consigue cuando dichas suposiciones contextuales, tanto del emisor como del receptor, se comparten mutuamente y son ostensibles y evidentes (Sperber y Wilson, 1986: 41).

El segundo principio sobre el que se asienta la TR, el Principio Comunicativo de Relevancia, se desarrolla en la misma línea que el primero. En el acto comunicativo, el receptor espera que el input sea lo suficientemente relevante como para que el esfuerzo que deba realizar merezca la pena y sea recompensado con un número elevado de efectos contextuales (Sperber y Wilson, 2004: 246). Por su parte, el emisor, en su deseo de que sus supuestos contextuales sean interpretados correctamente por el receptor, tiene la intención de generar un input que requiera el mínimo esfuerzo de procesamiento mental. En lo concerniente al contenido implícito, Sperber y Wilson recuperan el término "implicatura" del Principio Cooperativo de Grice para referirse al conjunto de suposiciones e

${ }^{10}$ Traducción de E. Leonetti del artículo de Ernst August Gutt, "On the Nature and Treatment of Implicit Information in Literary Translation: A Relevance-Theoretic Perspective", 1996, pp. 241 256. 
implicaciones contextuales de un enunciado que requiere un proceso de inferencia por parte del receptor. ${ }^{11}$

En última instancia, Sperber y Wilson asientan las bases de la TR en el Principio Cognitivo de Relevancia y el Principio Comunicativo de Relevancia. Según estos dos principios, el acto de comunicación consiste en un modelo ostensivo-inferencial en el que se parte de la premisa de que existe una intención informativa y comunicativa que el emisor desea que el receptor reconozca mediante la producción de un input. Este input genera expectativas de relevancia y su correcta interpretación dependerá de la cantidad de efectos contextuales generados y del esfuerzo requerido para su procesamiento. Para la comprensión del input, el receptor llevará a cabo un proceso de inferencia del contenido explícito e implícito. La interpretación de las implicaturas pondrá de manifiesto la confirmación de la hipótesis elaborada por el receptor al producirse una comunicación fructífera entre los dos interlocutores.

\section{LA TEORÍA DE LA RELEVANCIA APLICADA A LA TRADUCCIÓN: EL ENFOQUE COGNITIVO DE ERNST-AUGUST GUTT \\ E. A. Gutt (1989) propone un enfoque cognitivo fundamentado en la} Teoría de la Relevancia de Sperber y Wilson (1986), y entiende la traducción como un proceso o acto comunicativo. Más en concreto, E. A. Gutt asienta su enfoque en la premisa de que toda comunicación es un proceso ostensivo-inferencial en el que el emisor genera un input y el receptor lo interpreta infiriendo el conjunto de suposiciones contextuales transmitidas de manera implícita o explícita. En este proceso, el principio que regula que el receptor infiera el conjunto de suposiciones que el emisor desea transmitir es la relevancia.

Asimismo, el autor describe la traducción como un acto de comunicación secundaria en el que interviene un uso interpretativo del lenguaje: "a translation should convey the same interpretation as the original in secondary situations; (...) to be comunicable an interpretaction has to be consistent with the principle of relevance" (Gutt, 1989: 81). De este modo, en el proceso traslativo, el input en la lengua meta no se presenta "in its own right, but as a representation of an original source language stimulus" (Gutt, 1989: 79). El traductor construye un input ostensivo verbal que proyecta el original e intenta que sea fiel a las suposiciones contextuales óptimamente

\footnotetext{
${ }^{11}$ Sperber y Wilson distinguen dos tipos básicos de implicaturas, "una proposición puede verse más o menos implicada. Estará FUERTEMENTE IMPLICADA (...) si su recuperación es esencial de cara a conseguir una interpretación que satisfaga las expectativas de relevancia del receptor. Estará DÉBILMENTE IMPLICADA si su recuperación ayuda a la elaboración de tal interpretación, pero no es esencial en sí misma, ya que el enunciado sugiere un conjunto de implicaturas similares" (Sperber y Wilson, 2004: 261).
} 
relevantes que se derivan de este con el fin de hacerlas llegar al destinatario de la lengua meta. Por ende, el fin del traductor es conseguir una semejanza interpretativa entre el texto origen y el texto meta.

Las suposiciones contextuales de relevancia óptima del texto origen, transmitidas en forma de explicaturas e implicaturas, dependen del contexto que, esencialmente, debe ser compartido por el traductor y el comunicador de la lengua origen. De lo contrario, cuando un input ostensivo verbal se interpreta en un contexto cognitivo que difiere del contexto del comunicador de la lengua meta, la comunicación del mensaje no es fructífera. En este acto comunicativo ostensivo-inferencial en el que interviene un uso interpretativo del lenguaje, E. A. Gutt distingue dos modos de traducción, la directa y la indirecta:

\begin{abstract}
Just as direct quotation endeavours to convey exactly what someone else said, so direct translation endeavours to convey all the assumptions conveyed by the source text. Similarly, as indirect quotation may settle for conveying only part of the original message, so indirect translation may settle for conveying only those assumptions of the original text that are most relevant to the target audience. (Smith, 2002: 109-110).
\end{abstract}

La traducción indirecta, opción preferida por E. A. Gutt, tiene lugar cuando se produce la denominada "semejanza interpretativa incompleta", puesto que el traductor se aleja de conseguir la similitud completa entre las propiedades lingüísticas y estilísticas o pistas comunicativas ("communicative clues") del texto origen y meta y, por el contrario, opta por un acercamiento del contexto origen al contexto meta. ${ }^{12}$ De este modo, el traductor como emisor de un mensaje concreto, teniendo en cuenta el contexto cognitivo del autor y del receptor, comunica aquellas suposiciones contextuales 0 interpretaciones del texto meta que considere más relevantes y accesibles al lector, de manera que este pueda recuperarlas con el mínimo esfuerzo de procesamiento mental (Gutt, 1990: 142).

A modo de conclusión, E. A. Gutt propone un enfoque traductológico cimentado en la Teoría de la Relevancia para explicar que bajo los distintos tipos de traducciones subyace un acto comunicativo secundario en el que interviene un uso interpretativo del lenguaje. La traducción, como acto de comunicación ostensivo-inferencial, es un proceso interpretativo y puede adoptar dos formas principales: la traducción directa e indirecta.

\footnotetext{
12 Las pistas comunicativas se entienden como las propiedades textuales y estilísticas particulares del texto origen (propiedades semánticas, sintácticas y fonéticas, la onomatopeya, propiedades poéticas y expresiones idiomáticas, etc.) que guían las inferencias del receptor para lograr la interpretación implicada por el autor, quien establece una serie de propiedades textuales para conseguir "the intended interpretation" (Gutt, 2000: 161).
} 
En el primer caso, el traductor lleva a cabo una semejanza interpretativa completa, en la que se persigue transmitir las mismas suposiciones contextuales del autor del texto origen mediante una similitud lo más aproximada posible de las denominadas pistas comunicativas. Asimismo, el receptor deberá familiarizarse con el contexto del autor del texto origen para que se produzca dicha semejanza contextual. Por el contrario, la traducción indirecta se rige por el cumplimiento del Principio de Relevancia, a partir del cual el traductor transmitirá solo las suposiciones contextuales que sean óptimamente relevantes para el receptor sin exigirle un gran esfuerzo cognitivo para procesarlas. A diferencia de la traducción directa, el traductor hará más accesible el contexto del autor del texto origen con el fin de maximizar los efectos contextuales y, por ende, la relevancia.

6. ANÁLISIS PRAGMÁTICO-COGNITIVO DE TRES VERSIONES EN ESPAÑOL DE THE TELL-TALE HEART

En este apartado se realizará un análisis pragmático-cognitivo de un corpus de cuatro fragmentos extraídos de tres versiones en español de The Tell-Tale Heart de E. A. Poe. Para tal empresa, se adoptará el enfoque traductológico propuesto por E. A. Gutt con base en la Teoría de la Relevancia de Sperber y Wilson. El traductor, conocedor del autor del texto origen, del género literario al que este pertenece y del contexto históricocultural en que obra y autor se enmarcan, ha llevado a cabo la labor inferencial de las suposiciones que se implican en el texto origen y las ha transmitido mediante un conjunto de pistas comunicativas con el fin de producir los efectos cognitivos pretendidos por el autor del texto origen. De este modo, será de gran importancia identificar si el traductor ha llevado a cabo una "semejanza interpretativa" que responda al Principio Cognitivo de Relevancia para conseguir el mayor beneficio inferencial con el menor esfuerzo cognitivo posible por parte del receptor.

El corpus seleccionado se ha obtenido de las siguientes traducciones en formato papel. La primera de ellas responde al trabajo de Vicente López Folgado, (Cuentos extraordinarios. Barcelona: Ediciones Octaedro, 2012), la segunda pertenece al reconocido traductor y escritor Julio Cortázar (Cuentos, 1. Madrid: Alianza Editorial, 2007) y la tercera a los traductores Doris Rolfe y Julio Gómez de la Serna (Edgar Allan Poe Relatos. Madrid: Ediciones Cátedra, 2001). Las distintas versiones de The Tell-Tale Heart se han clasificado por orden alfabético con el objeto de facilitar al lector el seguimiento de su análisis. Por consiguiente, la letra $\mathrm{A}$ se ha asignado a la traducción de López Folgado, la B a la propuesta de Cortázar y la C a la versión en español de Rolfe y Gómez de la Serna. 
Fragmento n.o 1 , pág. $228^{13}$

"True! - nervous - very, very dreadfully nervous I had been and am"; "But why will you say that I am mad?"

A "iCierto! Soy nervioso, muy terriblemente nervioso; siempre lo he sido y lo sigo siendo. Pero ¿por qué os empeñáis en decir que estoy loco?".

$B$ " $i$ Es cierto! Siempre he sido nervioso, muy nervioso, terriblemente nervioso. Pero ¿por qué afirman ustedes que estoy loco?".

C " ¡Es verdad! Nervioso, muy, muy nervioso, lo he sido y lo soy; pero ¿por qué dirán que estoy loco?".

Es de reseñar el empleo del pronombre personal "you" al principio del relato. De este "you" podría interpretarse la intención más relevante del narrador protagonista creado por E. A. Poe, a saber, apelar y captar la atención absoluta del lector de la historia. De igual modo, el efecto de tal intención es hacer partícipe y testigo al receptor de la narración, instigándolo a racionalizar los motivos e impulsos de las acciones de su personaje principal, así como a sentir y a mimetizarse con el espacio sombrío y con el horror que lo empuja a cometer actos macabros.

El relato comienza con este narrador describiéndose a sí mismo, a modo de presentación, lo que permite al lector conocer su perturbado mundo interior. La hipérbole que acentúa el efecto de nerviosismo extremo del personaje principal puede entenderse, asimismo, como una táctica del autor para convencer al lector de que la locura y el caos que lo gobiernan pueden justificarse cuando se considera a nivel colectivo. La concepción negativa del individuo como entidad corrupta y salvaje del "Dark Romanticism" se hace eco en la fusión entre el individuo ficticio y el lector del relato.

Aún más, este nerviosismo exagerado se presenta como una dolencia $^{14}$ y como tal, se manifiesta mediante el tono agitado de las palabras del narrador, por la fuerza de la exclamación en "True!" y la reiteración de su discurso, "very, very dreadfully nervous". El efecto de intensificación, de la tortura que sufre el personaje, se expresa a su vez a través de los adverbios "very" y "dreadfully" por un lado, y por medio de la localización del atributo "nervous" al comienzo y al cierre de la oración, "nervous-, very, very dreadfully nervous". De esto se puede colegir que el efecto que genera el uso de la repetición, la hipérbole y la intensificación del discurso de este protagonista es un nerviosismo que trasvasa los límites

${ }^{13}$ Cada uno de los fragmentos analizados del texto origen han sido extraídos de la colección de relatos cortos de E. A. Poe The Fall of the House of Usher and other Writings. Poems, Tales, Essays and Reviews, publicada en el 2003 por la editorial británica Penguin Classics.

${ }^{14}$ Esta dolencia o trastorno denota también un tono de humor macabro mediante la exageración. 
racionales. Con esto, E. A. Poe convierte una experiencia individual y oculta en una experiencia compartida y sonante mediante el estrecho acercamiento entre el personaje y el lector.

En la segunda parte del fragmento, el autor emplea una pregunta retórica y enfatiza mediante la cursiva la palabra "will", con lo que pretende que el receptor valore y que se atreva a poner en entredicho cualquier prejuicio sobre la cordura/locura de su personaje. De la lectura de esta segunda oración, se puede inferir que el autor utiliza este verbo auxiliar para expresar sentido de volición o persistencia. Pero este sentido de volición o tenacidad concierne a esos "otros" (al receptor, tal vez a los críticos de su época), que se muestran sobremanera obstinados y lo (pre)juzgan como un individuo loco, cuando solo se trata de un nerviosismo extremo, de una enfermedad, que oculta la esencia destructiva, común a todo ser humano. ${ }^{15}$

Respecto de la traducción A, insta subrayar que López Folgado persigue la "semejanza interpretativa" y la relevancia en su versión. Sin embargo, el efecto de nerviosismo hiperbólico del original se reduce con la recreación de un ritmo algo más pausado, "Soy nervioso, muy terriblemente nervioso;". No obstante, el traductor sí logra preservar la intensidad del nerviosismo mediante el adverbio "terriblemente", además de conservar el efecto de horror y de locura pretendido por el autor. En cuanto a la segunda parte del fragmento, cabe decir que López Folgado hace una excelente labor al generar un efecto enfático con el trasvase de "will + say" > "empeñáis", ya que este auxiliar denota además volición o insistencia por parte de aquellos "otros" ("you > os, -áis), análogo al de la versión original. Finalmente, se puede argüir que, en este ejemplo, el traductor consigue acercar los contextos cognitivos del autor y del receptor del texto meta al estructurar sintácticamente el fragmento de manera que se ajuste a la lengua meta y no exija un mayor esfuerzo cognitivo por parte del lector para inferir las suposiciones transmitidas.

En la versión traducida $\mathrm{B}$, a diferencia de la anterior, Cortázar reproduce el efecto de inquietud característico del nerviosismo con la repetición tanto de la premodificación del atributo como del adjetivo, "nervioso, muy nervioso, terriblemente nervioso". Un aspecto de interés que merece ser mencionado es que López Folgado en la versión A, y el traductor en la presente versión implican que el estado mental del narrador forma parte de la cualidad del personaje y no es una consecuencia que se deriva de su irracionalidad. Esto se colige a partir del adverbio temporal

\footnotetext{
${ }^{15}$ De esta defensa de la locura/cordura, el lector conocedor del contexto social del autor podría inferir que E. A. Poe subvierte aquí la "insanity defense" en "sanity defense"; a saber, la reforma aplicada en los tribunales a comienzos del siglo XIX para poder alegar la demencia en la ejecución de un delito y librar al acusado de la pena impuesta.
} 
"siempre" <"I had been and am". La diferencia entre las dos versiones radica en que en la $A$, se recalca, al igual que en la original, la idea de que en el presente, el narrador no ha dejado de ser/estar nervioso, "siempre lo he sido y lo sigo siendo", mientras que en la versión B, esto se muestra como "Siempre he sido nervioso", lo que minimiza la hipérbole que convierte el nerviosismo en una dolencia pertinaz. Por su parte, en cuanto a la traducción de "will + say", Cortázar opta por verter el verbo "say" como "afirmáis" ("asegurar o dar por cierto algo") y omite la carga enfática del verbo auxiliar "will", por lo que no transmite la misma implicatura que el original: el empeño que se inferiría de este modal.

Por último, la versión $\mathrm{C}$ se caracteriza por romper con el ritmo de la primera oración. Por ende, se produce una minimización del efecto que reafirma la cualidad nerviosa del personaje. El aspecto que más llamaría la atención en esta versión es la ausencia total de ese efecto de persistencia que se muestra en la versión de López Folgado. Los traductores Rolfe y Gómez de la Serna vierten "will + say" como "¿por qué dirán que estoy loco?", lo que resta incluso ese sentido de humor macabro que acompaña al "por qué os empeñáis" de la versión A y a la justificación de la locura del personaje principal con su trastorno nervioso exagerado.

Fragmento $\mathrm{n} . \mathrm{0}$ 2, pág. 229

"His room was as black as pitch with the thick darkness, (for the shutters were closed fastened, through fear of robbers) and so I Knew he could not see the opening of the door, and I kept pushing it on steadily, steadily"

A "Su alcoba estaba negra cual boca de lobo por la oscuridad, ya que los postigos estaban bien cerrados por miedo a los ladrones. Por eso sabía yo que él no podía ver la abertura de la puerta, de modo que continué empujándola muy despacio, poquito a poco".

B Su cuarto estaba tan negro como la pez, ya que el viejo cerraba completamente las persianas por miedo a los ladrones; yo sabía que le era imposible distinguir la abertura de la puerta, y seguí empujándola suavemente, suavemente".

C "Su cuarto estaba tan negro como un pozo, con una densa oscuridad (porque las contraventanas estaban bien cerradas por miedo a los ladrones), y por eso yo sabía que no podía ver la abertura de la puerta y seguí empujándola, empujándola sin cesar".

En este fragmento, el protagonista se adentra sigilosamente en la habitación del anciano para acabar con su vida en el silencio de la noche. La profunda oscuridad que envuelve a la alcoba de la vieja casa crea un efecto sobrecogedor que vaticina la muerte por un lado, y la locura del 
verdugo, que después lo delatará como autor del crimen, por otro lado. E. A. Poe explota las connotaciones negativas que acompañan a la noche y a la oscuridad, la destrucción del individuo, tan recurrentes en la literatura del género gótico. Además, tampoco es de extrañar el énfasis que recae en la vulnerabilidad del hombre, bien encarnada en la figura del anciano, "for the shutters were closed fastened, through fear of robbers", o bien reflejada mediante la torturada mente del personaje principal. De nuevo, E. A. Poe pincela la escena con su peculiar humor macabro, ya que el viejo se ha arrojado voluntaria e inconscientemente a las fauces de la muerte.

El efecto de terror se eleva cuando el autor del relato provoca la muerte no natural del anciano en un entorno aislado (la habitación > la mente del protagonista), silente y envuelto en las sombras. Este efecto se funde con la calma y el sigilo con el que el narrador entra en este espacio de tensión y suspense, "I kept pushing it on steadily, steadily". El tiempo se detiene en un instante para abrazar a la muerte.

López Folgado consigue preservar en su totalidad los efectos de la versión original que se mencionan en los párrafos anteriores. A modo de ejemplo, en la versión traducida $A$, la imagen mental de profunda oscuridad y mal augurio se plasma mediante la comparación "(...) was as black as pitch with the thick darkness" > "(..) negra cual boca de lobo", expresión muy familiar para el lector meta que, a su vez, presagia la muerte del decrépito en el lecho, su ataúd. Para reproducir el efecto de dilatación en el tiempo, calma e intriga, que paradójicamente crea un estado de inquietud que incita al receptor a continuar el relato, López Folgado emplea dos sintagmas adverbiales, cada uno con sus respectivos modificadores de intensidad, "steadily, steadily" > "muy despacio, poquito a poco".

En lo que concierne a la versión traducida B, Cortázar utiliza la expresión "tan negro como la pez" para comparar el color de esta sustancia con la habitación en la que yace el anciano, "His room was as black as pitch with the thick darkness". Según el Diccionario de la Real Academia Española (2001), la "pez negra" es aquella que "resulta de la destilación de las trementinas impuras, y es de color muy oscuro por quedar mezclada con negro de humo". En este caso, el símil entre la negrura que caracteriza la pez, la de la noche y la oscuridad es, hasta cierto punto, extraño para el lector meta. En consecuencia, tanto el efecto de suspense y terror del original, así como la inferencia de la prevalencia de la irracionalidad y la sistematicidad de las acciones por parte del protagonista no se comunican con tanta facilidad y claridad como en la versión A. Además, el traductor minimiza el efecto del aislamiento sombrío, de la oscuridad absoluta y la inferencia de la muerte inminente al verter "shutters" por "persianas", y no como "postigos" o "contraventanas" como en las versiones traducidas A y C. Asimismo, reduce el toque humorístico característico del autor, puesto que 
por miedo a los ladrones el anciano se entrega a su verdugo. El aislamiento y el miedo conducen a la locura y, por lo tanto, a la autolisis, esencia del individuo.

En lo relativo al trasvase de los adverbios "steadily, steadily" del original, insta señalar que Cortázar atenúa el efecto de inquietud que se desprende de la firmeza con la que el personaje principal abre lentamente la puerta de la alcoba. El lexema "suavemente" de la versión B implica lentitud en el movimiento, pero no acentúa el control que ejerce el narrador en su paradójico estado de locura.

En última instancia, Rolfe y Gómez de la Serna, en la versión traducida $\mathrm{C}$, abogan por trasladar "His room was as black as pitch with the thick darkness" como "Su cuarto estaba tan negro como un pozo, con una densa oscuridad". El resultado de esta traducción es un efecto de incertidumbre y terror, de oscuridad y desasosiego, análogo al de la versión original. El receptor felizmente puede inferir que la alcoba envuelta en las sombras refleja la imagen del fondo profundo del pozo de la muerte. A diferencia de las versiones $\mathrm{A}$ y $\mathrm{B}$, los traductores vierten el adverbio "steadily, steadily" como "empujándola, empujándola sin cesar", lo que rompe con el efecto de calma, control del narrador y tensión de toda la escena macabra. El lexema "empujar" alude al empleo de fuerza contra algo o alguien, según el Diccionario de la Real Academia Española (2001). De este modo, el lector meta infiere erróneamente una connotación distinta a la pretendida por el autor del relato, es decir, el verdugo actúa por el influjo de sus impulsos y raudo, abre la puerta. Para el protagonista perturbado, la muerte lenta y calculada es la que culmina en la locura y en esta, el placer (de la lectura), la "unidad de efecto".

Fragmento $\mathrm{n} . \mathrm{0}$ 3, pág. 229

"He was still sitting up in the bed - listening; - just as I have done,
night after night, hearkening to the death watches in the wall (...)
Presently, I heard a slight groan and I knew it was the groan of
mortal terror"
A "Seguía aún sentado en la cama, escuchando, igual que había hecho
yo, una noche tras otra, oyendo las carcomas en la pared (...) De pronto
oí un débil gemido y pensé que era un gemido debido al terror mortal".
B "Seguía sentado, escuchando...tal como yo lo había hecho, noche tras
noche, mientras escuchaba en la pared los taladros cuyo sonido anuncia
la muerte (...) Oí de pronto un leve quejido, y supe que era el quejido que
nace del terror".
C "Todavía estaba sentado en la cama, escuchando igual que he hecho
yo noche tras noche, escuchando en la pared la carcoma de la muerte
(...) Al rato oí un gemido, y me percaté de que era el gemido de un terror


mortal".

En el fragmento de la versión original, el autor crea una escena característica del género gótico. La noche, las sombras, el silencio y el miedo que se deriva de saber que alguien está observando y vigilando elevan sobremanera el efecto de tensión y terror. Más en concreto, el anciano percibe la presencia del personaje principal, mas es incapaz de moverse, ya que el pavor lo invade. Sin embargo, esta sensación tan poderosa aguza los sentidos, en especial, el del oído al tratarse de un escenario envuelto en la oscuridad. Insta señalar que este es el único sentido que lleva a la locura al protagonista puesto que, como subraya en líneas anteriores, en su estado nervioso extremo, posee la habilidad de escuchar lo mundano y lo infernal. De esto se puede colegir que E. A. Poe explicita que la observación de lo material, la imaginación y el tormento individual se funden en un plano de nebulosa.

Por extensión, los verbos "listening" y "hearkening" se tiñen de una connotación negativa, ya que vaticinan la muerte que va a ejecutarse. ${ }^{16}$ Este designio fatal se representa explícitamente mediante "the death watches in the wall". Las carcomas ("death watches") o escarabajos del reloj de la muerte se caracterizan por el tímido, mas constante golpeo en la madera que roen. Este sonido, a pesar de ser débil, es perfectamente audible al oído humano. En este caso, el lector del relato infiere sin esfuerzo que el personaje principal ha condenado al anciano a la muerte, que ocurrirá en su alcoba en el silencio de la noche, aislado del mundo exterior. Al igual que el anciano escucha el susurro del miedo, del mismo modo el narrador escucha en este fragmento el suave tic-tac de la muerte y, más adelante, los fuertes delatores latidos del decrépito difunto. Este efecto de horror paralizante llega a su culmen con el gemido de "mortal terror" del anciano.

En la versión traducida $A$, es de reseñar el uso de los verbos "escuchar" y "oír" como equivalentes para "listening" y "hearkening". Mientras que "listening" > "escuchar" reproduce el efecto de suspense distintivo de esta escena, la opción por verter el verbo "hearkening" como "oír" minimiza el efecto intensificador de la tortura interior del narrador que se desprende de "escuchar atenta e intencionadamente" el golpeo incesante de los escarabajos del reloj de la muerte carcomiendo la pared, su mente. Es decir, el sonido vaticinador de la muerte se percibe en un segundo plano.

${ }^{16}$ Los verbos "listen" y "hearken" se trasvasan al español indistintamente como "escuchar". Sin embargo, en la lengua origen "hearken" se emplea con más frecuencia con un efecto poético. En el ejemplo seleccionado, este verbo tiene como complemento directo "the death watches", es decir, las carcomas o escarabajos del reloj de la muerte que simbolizan el óbito de una persona. El lector puede incluso inferir que el personaje principal es la viva imagen de la muerte que espera el momento oportuno para llevarse el último hálito de su presa. 
Por su parte, Cortázar prefiere el signo de los puntos suspensivos, "Seguía sentado, escuchando..." para reforzar el efecto de tensión que el autor del relato evoca. Por el contrario, López Folgado realiza una elección más acertada con la coma (,) para el guión (-) de la versión original, ya que este signo ortográfico expresa felizmente la pausa aclaratoria y abrupta que enfatiza el cinismo macabro del protagonista. Los puntos suspensivos, en cambio, indicarían un estado dubitativo para describir a este personaje. Asimismo, en la versión traducida $\mathrm{B}$, el traductor trasvasa erróneamente tanto el efecto de horror y suspense como la interpretación del símbolo de los escarabajos del reloj de la muerte que corroen la madera con su débil tic-tac, y opta por "(...) los taladros cuyo sonido anuncia la muerte". La gradación de intensidad de la tortura y la locura, que se plasma en consonancia con el desarrollo de la historia, es inexistente con la imagen ensordecedora de "los taladros".

En último término, cabe destacar de la versión de Rolfe y Gómez de la Serna la traducción de "death watches" por "carcoma de la muerte". En este caso, los traductores consideran el trasvase del lexema "death" independientemente de "watches", cuando "death watches" se categoriza como un nombre compuesto en la lengua origen, cuyo equivalente en la lengua meta es "carcoma" simplemente. Al añadir el sintagma preposicional de complemento del nombre "de la muerte" explicita el simbolismo que el autor del texto origen pretende que el lector descubra. Si bien minimiza el esfuerzo de procesamiento mental que debe realizar el receptor de la lengua meta, también resta la "magia" que entraña deducir el sentido de la metáfora, pues el relato y el texto meta ya han proporcionado suficientes pistas comunicativas como para que el receptor encuentre ambigüedad en esta figura. Otro aspecto importante es el trasvase erróneo del conector temporal "Presently" > "Al rato", que indica que algo ocurre de manera repentina e inesperada; el gemido del anciano rompe la tensión por un instante para, en el siguiente, magnificar su horror. En la versión C, igualmente, se prescinde del adjetivo "slight" ("débil"), lo que reduce el efecto de inquietud y terror que el autor ha pretendido evocar en el texto original. El decrépito, víctima de su estado y de la muerte acechante en la noche, tan solo es capaz de emitir un leve gemido debido al pavor que lo invade. Las habilidades humanas, excepto el sentido del oído que incrementa el miedo, se apagan.

Fragmento $n .=4$, pág. 232

"Oh God! What could I do? I foamed - I raved - I swore! I swung the
chair upon which I had been sitting, and grated it upon the boards, but
the noise arose over all and continually increased. It grew louder -
louder - louder!"


A “¡Oh, Dios!, ¿Qué podía hacer yo? ¡Eché espumarajos de rabia, deliré, juré! Balanceaba la silla en la que estaba sentado y la hacía chirriar contra el suelo, pero el ruido superaba todo y crecía continuamente. ¡Se oía más alto, más alto, más alto!"

B “¡Oh, Dios! ¿Qué podía hacer yo? Lancé espumarajos de rabia...maldije...juré... Balanceando la silla sobre la cual me había sentado, raspé con ella las tablas del piso, pero el sonido sobrepujaba todos los otros y crecía sin cesar. ¡Más alto...más alto...más alto!"

C “¡Oh, Dios! ¿Qué podía yo hacer? ¡Echaba espuma por la boca, deliraba, maldecía! Agarré la silla en la que había estado sentado y la arrastré por las tablas del suelo, pero el ruido se oía por encima de los demás y seguía creciendo. Se hizo más fuerte..., más fuerte..., fortísimo".

Este fragmento refleja la desesperación del protagonista por silenciar su locura, que se plasma mediante los ensordecedores latidos del corazón del anciano ya difunto que retumban en su mente. Este estado de cólera se exacerba con la ira que surge a partir del y que se contrasta con el comportamiento pasivo de los agentes de policía, ajenos al corazón delator y al crimen cometido. De igual modo, el enojo exagerado y la irracionalidad del personaje principal se manifiestan en el uso de un lenguaje violento y de pausas abruptas en su discurso, "I foamed- I raved - I swore!", "(...) louder - louder - louder".

De esta escena, asimismo, es factible inferir el tono humorístico con el que el autor impregna el relato. La pasividad, o más bien necedad de la policía, que tiene ante sí al perpetrador del asesinato del anciano, agudiza la naturaleza perturbada del narrador; "What could I do?", se pregunta el protagonista de forma retórica e irónica como respuesta a la vaciedad de los agentes y a la irracionalidad que lo carcome. Los toques burlescos y la locura se hacen claramente manifiestos cuando el narrador explica que "I swung the chair upon which I had been sitting, and grated it upon the boards", "(...) louder - louder - louder", mientras que los únicos testigos de su estado permanecen ignorantes a lo acontecido esa noche.

En la versión traducida A, López Folgado comunica felizmente el mismo énfasis y similares inferencias, en principio, al preservar la cursiva del verbo auxiliar "could" del original. Por ende, el receptor de la lengua meta deduce sin esfuerzo alguno tanto la desesperación del protagonista en su lucha interior por acallar los latidos cada vez más fuertes y más rápidos del decrépito, como la furia causada por la ignorancia de los agentes, incapaces de percibirlos. De la misma manera, el traductor consigue transmitir la pincelada de humor macabro del autor del relato, ¿qué más podría hacer el narrador, sino burlar a la muerte con la locura y la irónica necedad de los individuos encarnada en la policía? 
En lo relativo a la brusquedad y fuerza con la que el personaje principal expresa su locura y cólera, "I foamed- I raved - I swore!", el traductor de la versión A opta por "¡Eché espumarajos de rabia, deliré, juré!", es decir, utiliza un discurso pausado, abrupto y acentuado con la exclamación, con el que mantiene el estado nervioso extremo y delirante del narrador. Otro aspecto que debe recalcarse es el trasvase del sintagma "It grew louder - louder - louder!" de la versión original como "¡Se oía más alto, más alto, más alto!", en el que, de nuevo, se preserva el efecto in crescendo de la enajenación del protagonista que llega finalmente a su clímax. Al igual que E. A. Poe juega con la repetición y la hipérbole "I foamed-I raved - I swore!", "It grew louder - louder - louder!", López Folgado logra verter el contraste entre la locura y la ira, y la vacuidad de los agentes en la escena del crimen.

Respecto de la versión B, Cortázar subraya el verbo "do" > "hacer", lo que minimiza la tensión, la furia e incluso la ironía que el autor atribuye al auxiliar "could". El protagonista pierde, hasta cierto punto de manera deliberada, la capacidad mental para manejar la situación, ya que lo invade la locura que, irónicamente, se ha apoderado de él. El traductor erróneamente usa un doblete léxico “(...) I I raved - I swore!" > "i(...) maldije...juré!, cuando el sentido del verbo "rave" es "delirar". En consecuencia, el traductor resta énfasis a la turbación del protagonista que intenta enmudecer los latidos que hablan por el anciano mediante el chirriar o rechinar de la silla de la versión A. Paradójicamente, este sonido agudo y desapacible simboliza los latidos y el tormento del narrador.

Por otro lado, los puntos suspensivos en la traducción de Cortázar, “lancé espumarajos de rabia...maldije...juré...", por el contrario, reducen la intensidad de la cólera y del nerviosismo del personaje principal. El empleo de este tipo de puntuación en el discurso de un narrador torturado reproduce un efecto de duda, temor, vacilación o suspense, que aparece en discordia con la escena delatora de la locura, la frialdad y la ironía del verdugo. Esto mismo es aplicable a la utilización de los puntos suspensivos en el sintagma "It grew louder - louder - louder!" > ¡Más alto...más alto...más alto!".

En cuanto a la versión de Rolfe y Gómez de la Serna, cabe reseñar que la traducción que proponen para "I swung the chair upon which I had been sitting, and grated it upon the boards" > "Agarré la silla en la que había estado sentado y la arrastré por las tablas del suelo" dista completamente de la versión original. Aparte de la traducción incorrecta del sentido de determinados lexemas, insta añadir que si por un lado, los traductores pretenden recrear un efecto de máxima locura en el narrador, esta intención, en cambio, debilita el efecto de locura pretendido por el autor que resulta de no poder mitigar el nerviosismo exagerado con el que la locura se 
asocia. A esto se añade el hecho de que en la versión $\mathrm{C}$, el uso de los puntos suspensivos seguidos por una coma genera un efecto moderador contrario al estado que Rolfe y Gómez de la Serna, en un principio, atribuyen al personaje principal. La elección del superlativo "fortísimo" en esta última secuencia, de igual modo, se contrapone al uso de este signo de puntuación que indica duda, pausa y temor con respecto al verdugo.

En resumen, la versión en español A de estos cuatro fragmentos del relato The Tell-Tale Heart es la más acertada en cuanto a que cumple con la labor de conseguir la "semejanza interpretativa" de la traducción y con el objeto de ajustar el acto de comunicación secundaria, ostensivo-inferencial al Principio Comunicativo de Relevancia.

\section{CONCLUSIONES}

Ernst-August Gutt (1989) concibe la traducción como comunicación ostensiva-inferencial secundaria. En relación al papel del traductor, este actúa primero como lector y comunicador del texto origen. Su labor consiste en verter el mensaje implicado en el texto meta, creando un input ostensivo verbal que manifieste el original de la lengua origen. Para ello, el traductor debe ser fiel a las suposiciones contextuales óptimamente relevantes del autor y maximizar los efectos cognitivos que se ponen de relieve en el texto origen para hacerlas llegar al destinatario de la lengua meta.

El análisis traductológico de los cuatro fragmentos extraídos de las tres versiones españolas citadas del relato The Tell-Tale Heart indica que, por lo general, cada traductor ha pretendido trasvasar un máximo de aquellas pistas comunicativas más relevantes (valores semánticos, estilísticos y sintácticos) del texto origen que permitan estrechar lazos entre las suposiciones contextuales del autor y las del receptor del texto meta. Se trata, pues, de una traducción indirecta en la que prima el Principio Comunicativo de Relevancia y la "semejanza interpretativa", de modo que la interpretación del mensaje implicado por E. A. Poe se ha realizado con el menor esfuerzo de procesamiento cognitivo.

Se observa que las versiones A, B y C preservan y maximizan los efectos cognitivos del texto origen, de manera que el lector infiere con un mínimo esfuerzo cognitivo gran parte de las suposiciones que el autor del relato ha pretendido transmitir de modo implícito. Aun así, también se han abordado aquellos ejemplos en los que las traducciones $\mathrm{B}$ y $\mathrm{C}$, en concreto, han distado de conseguir una "semejanza interpretativa" y de ajustarse al Principio Comunicativo de Relevancia, por lo que la comunicación de las suposiciones contextuales del autor del relato no ha sido fructífera.

REFERENCIAS BIBLIOGRÁFICAS 
Alsen, Eberhard, The New Romanticism: A Collection of Critical Essays. New York: Garland Publishing, 2000.

Álvarez FAEDO, Mํㅡㄹ José, "The Tales of Edgar Allan Poe: A study of his Creative Process". En: The American Short Story: New Perspectives. Papers of the I International Conference on American Literature. Santiago de Compostela: Universidad de Santiago, 1997, pp. 113118.

BuELL, Lawrence, Columbia Literary History of the United States. New York: Columbia University Press, 1988.

CAstillo, F. J, "Notas sobre los relatos de Poe: las piezas góticas". En: Revista de Filología, 28, 2010, pp. 11-30.

CERVANTES, Sergio A., "La filosofía trascendentalista de Emerson". En: Clfo, 5, 21, 1997, pp. 173-193.

CoY, Juan José, Entre el espejo y el mundo. Texto literario y contexto histórico en la literatura norteamerican (I). Valencia: Departament de Filologia Anglesa i Alemanya, 2004.

DínÇER, Figun, "The Light and Dark Romanticim Features in Irving, Hawthorne and Poe". En: The Journal of International Social Research, 3/10, 2010, pp. 218-224.

FoERSTER, Norman, "The Romantic Revolt”. En: American Poetry and Prose. New York: Houghton-Mifflin, 1970, pp. 257-59.

GallowAY, David, "Introducción". En: The Fall of the House of Usher and Other Writings. London: Penguing Books, 2003, pp. XVII-LVI.

Goddu, Teresa A., Gothic America: Narratve, History, and Nation. New York: Columbia University Press, 1997.

Goodman, Russell B., American Philosophy and the Romantic Tradition. Cambridge: Cambridge University Press, 1990.

Grice, H. Paul, Speech acts. New York, San Francisco and London: Academic Press, 1975.

GUTT, Ernst-August, "On the Nature and Treatment of Implicit Information in Literaty Translation: A Relevance-Theoretic Perspective". En: International Journal of Translation Studies, 8, 1996, pp. 241-256.

-, "A theoretical account of translation - without a translation theory". En: Target: International Journal of Translation Studies, 2/2, 1990, pp. 135-164.

-, "Translation and Relevance". En: UCL Working Papers in Linguistics, 1, 1989, pp. 75-95.

-, "Textual Properties, Communicative Clues and the Translator." En: M. Pilar Navarro-Errasti, Rosa Lores-Sanz, Silvia Murillo-Ornat and Carmina Buesa-Gómez (eds.). Transcultural Communication: Pragmalinguistic Aspects. Zaragoza: Anubar, 2000, pp. 161-170. 
HUME, Robert, "Exuberant Gloom, Existential Agony, and Heroic Despair: Three Varieties of Negative Romanticism". En: The Gothic Imagination: Studies in Dark Romanticism. Pullman: Washington State University Press, 1974, pp. 109-127.

IRISARRI Vázquez, Fco. J., "La recepción del romanticismo alemán en Norteamérica: El idealismo de F. J. Schelling en el trascendentalismo de H. D. Thoreau". En: Anuario de la Asociación de Alumnos de Postgrado de Filosofía TALES, 1, 2008, pp. 123-133.

MathIESSEN, F.O., American Renaissance. United States: Oxford University Press, 1940.

$\mathrm{NASH}$, Roderick, Wilderness and the American Mind. United States: Yale University, 2001.

PaKditaWAN, Sirinya, Aspects of American Romanticism in Short Stories by Edgar Allan Poe and Nathaniel Hawthorne. Germany: Grin Verlag, 2007.

PARRINGTON, V. L., Main Currents in American Thought. Oklahoma: University of Oklahoma Press, 1987.

PECKHAM, Morse, "Toward a Theory of Romanticism". En: PMLA, 66, 1951, pp. 5-23.

POE, Edgar A., The Fall of the House of Usher and other Writings. Poems, Tales, Essays and Reviews. London: Penguin Classics, 2003.

-, Cuentos extraordinarios. Trad. Vicente López Folgado. Barcelona: Ediciones Octaedro, 2012.

-, Relatos. Trads. Doris Rolfe y Julio Gómez de la Serna. Madrid: Ediciones Cátedra, 2001.

_, Cuentos, I. Trad. Julio Cortázar. Madrid: Alianza Editorial, 2007.

POPESCU, Andreea, "Immolation of the Self, Fall into the Abyss in Edgar Allan Poe's Tales". En: Partium Journal of English Studies, 2012, pp. 1-8.

RoBINSON, David M., "Transcendentalism and Its Times". En: The Cambridge Companion to Ralph Waldo Emerson. Cambridge: Cambridge University Press, 1999, pp. 13-30.

REYNOLDS, David S., Beneath the American Renaissance. New York: Oxford University Press, 2011.

Sperber, Dan; DeIRDRE, Wilson, Relevance: Communication and Cognition. London: Basil Blackwell, 1986.

-, "La Teoría de la Relevancia". Trad. Francisco Campillo García. En: Revista de Investigación Lingüística, 7, 2004, pp. 237-286.

SMITH, Kevin, "Transaltion as Secondary Communication. The Relevance Theory Perspective of Ernst-August Gutt". En: Acta Theologica Supplementum, 2, 2002, pp. 107-117. 
SCHULman, Robert, "Poe and the Powers of the Mind". En: ELH, 37, 2, 1970, pp. 245-262.

TAYLOR, Bron, Encyclopedia of Nature and Religion. London and New York: Continuum, 2005.

Thompson, G. R., "Poe and the Writers of the Old South". En: Columbia Literary History of the United States. New York: Columbia University Press, 1988, pp. 262-77.

WALSH, Christopher, "'Dark Legacy': Gothic Ruptures in Southern Literature”. Critical Insights: Southern Gothic Literature. New York: Salem Press, 2013, pp. 19-34. 